\title{
Dimensiones de una masacre en la escuela: traducción intersemiótica en We need to talk about Kevin
}

\section{Moreiras, Diego A.}

Resumen:

El presente trabajo aborda los procesos de transformación de la materia lingüística literaria en discurso cinematográfico a partir de un caso específico: We need to talk about Kevin, libro de Lionel Shriver y filme de Lynne Ramsay. Me interesa, en primer lugar, centrarme en las transformaciones que sufre la materia lingüística en su traducción intersemiótica a otra materialidad significante. Además, resulta pertinente, en segundo lugar, compartir algunas reflexiones sobre las disputas, consideradas en términos de lo político, en torno a la institución escolar construida en el libro y en el filme.

\section{Cuadernos del Centro de Estudios de Diseño y Comunicación № 61}



ISSN: 1668-0227

Imágenes/escrituras:

trazos reversibles

Año XVII, Marzo 2017, Buenos Aires, Argentina | 176 páginas

descargar PDF

ver índice de la publicación

Ver todos los libros de la publicación

compartir en Facebook

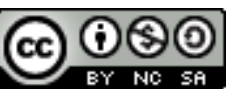

Esta obra está bajo una Licencia Creative Commons Atribución-NoComercialCompartirlgual 4.0 Internacional

Palabras clave:

traducción intersemiótica - discurso - masacres en escuelas - lo político - conflictos en escuelas.

$\left(^{*}\right)$ Profesor en Enseñanza Primaria por la Escuela Normal Superior Dr. Agustín Garzón Agulla, Licenciado en Comunicación Social y Magister en Investigación Educativa por la Universidad Nacional de Córdoba. Se desempeña como Profesor Asistente por concurso en el Profesorado Universitario de Comunicación Social de la Escuela de Ciencias de la Información (UNC). Se encuentra cursando el Doctorado en Semiótica del Centro de Estudios Avanzados (UNC) y es becario de CONICET. Integra el Grupo de Estudios de la Imagen e integra y ha integrado Proyectos y Programas de Investigación y Extensión en diversas unidades académicas de la UNC.

\section{Presentación}

We need to talk about Kevin es la historia de una masacre en un contexto escolar, planteada desde el núcleo familiar de Kevin, adolescente que ejecuta la masacre. El libro fue publicado por primera vez en el año 2003. Su autora es Lionel Shriver y se presenta como un conjunto de cartas que Eva, madre de Kevin y esposa de 
Franklin, le escribe a su marido luego de la masacre del jueves1. La película fue estrenada en 2011, su directora es Lynne Ramsay y está basada en el texto. Libro y película comparten el mismo título.

Si bien lo familiar es el centro de la historia, el punto de vista del relato constituye una característica particular tanto del filme como del libro: Eva, la madre de Kevin, es el punto de focalización para narrar esta historia y, a través de su personaje, accedemos a los eventos que llevan hasta el jueves, día de la masacre. Desde allí, se nos muestra el devenir de la cotidianeidad de Eva con posterioridad al juicio y durante los dos primeros años del encarcelamiento de su hijo.

Hay, además, un segundo elemento que diferencia a We need de otras historias sobre matanzas en escuelas2. La decisión de Kevin no nace de una situación puntual o reiterada de acoso escolar, de violencia o maltrato ejercida hacia él por sus compañeras/os. En este sentido, la historia propone (y complejiza) un personaje que, lejos de ser la víctima de situaciones de acoso en la escuela, en muchas oportunidades es quien las genera.

En este escrito, nos proponemos desarrollar dos ideas de trabajo que pueden considerarse articuladas entre sí3. La primera establece que en el libro es preponderante la construcción del personaje de Kevin, a partir de los recuerdos de Eva, que hace de narradora. En ese juego, Eva escribe desde un tiempo cero de la enunciación establecido claramente por la fecha de cada una de las cartas, con posterioridad al fatídico jueves y antes del segundo aniversario de la masacre. Su escritura, no obstante, presenta un predominio de relatos sobre el pasado, en un diálogo diferido, propio del género epistolar, con su marido. El presente de Eva es de una soledad abrumadora y la inquietud por la ausencia de su marido, Franklin, y su hija, Celia, va a crecer en el espectador a partir de estrategias de montaje. En la película, la vida interior de Eva queda reflejada solamente en su rostro: desaparecen sus reflexiones y pensamientos como tales (importantes y explícitos en el libro). Solamente tenemos el cuerpo y los gestos de Tilda Swinton. Kevin, aquí, se presenta a sí mismo a través de sus acciones y en menor medida, de sus palabras. El relato está focalizado igualmente en Eva, pero lo que llegamos a saber de ella es considerablemente menos.

La segunda idea de trabajo tiene que ver con lo escolar. Si bien la historia de We need tiene como eje lo familiar y ese universo doméstico que Kevin hace estallar el día jueves, en el libro se nos ofrecen múltiples escenas que transcurren en el ámbito de la escuela. Eva narra acontecimientos que tienen lugar a lo largo de la escolaridad de Kevin y que involucran a diferentes actores de ese mundo escolar. En la película, en cambio, la tragedia familiar se impone; es la que aparece preponderantemente en campo. La masacre en la escuela es una sola escena fragmentada y distribuida durante buena parte de la primera mitad del filme; hacia el final tan sólo vemos a Kevin disparando flechas (sin ver el destino de las mismas) y saludando al gimnasio vacío, al finalizar. En la adaptación de Lynne Ramsay al cine, We need... pierde casi todas las imágenes de la tragedia pública de la historia. Si bien es verdad que la imposibilidad de la vida en el presente de la enunciación de Eva no tiene que ver solo con su tragedia personal, sino sobre todo con las consecuencias en lo público de la masacre, con su dimensión de destrucción de las vidas ajenas, lo escolar es menos mostrado en el filme (que en el libro): así, se difumina en gran medida lo que es del orden de lo político y de la capacidad de (re)acción de los sujetos.

Por lo anterior, estamos en condiciones de afirmar que We need to talk about Kevin se aparta de otros relatos que podrían ser considerados similares en su temática y en la representación que construyen sobre las masacres escolares y por eso justifica nuestra atención. 
Ahora bien, ¿existe una forma predominante para representar masacres en escuelas? O incluso antes que eso, podríamos preguntarnos: ¿existe una forma de representación específica de masacres? (Imagen 1) De la(s) masacre(s)

Un aporte en dirección a esa respuesta lo realizan José E. Burucúa y Nicolás Kwiatkowski (2009) cuando rastrean la (re)construcción literaria, histórica y pictórica de algunas importantes masacres de la humanidad.

En las diferencias que los autores encuentran entre las masacres antiguas y las modernas, nosotros podemos recuperar algunos elementos de interés: las primeras, representan las matanzas míticas (de los santos inocentes, por ejemplo) desarrolladas durante el Medioevo, en las que se muestra a los perpetradores en la posición vertical, con el brazo en alto que blande el arma homicida a la manera de la figura tradicional del luchador victorioso, mientras que las mujeres y otras víctimas comienzan a desmoronarse, presa de la desesperación y de la angustia. Toda la escena (...) despliega una superficie con cuerpos entrelazados en alusión al caos de las matanzas, y reserva también un lugar en el fondo para los testigos silenciosos del suceso. (Burucúa y Kwiatkowski, 2009, p. 72-73).

En ellas, no hay dudas acerca de los roles que juega cada sujeto. Los perpetradores son fácilmente distinguibles por sus rasgos y sus acciones. Los autores afirman que, luego, este primer modelo plástico se transforma mediante la superposición con otro: el de la cacería de animales salvajes. En esas representaciones, las víctimas aparecen animalizadas y en gran medida, los victimarios como héroes. Esta es la composición que adoptan las representaciones de las masacres-genocidios contemporáneas, en las que las víctimas son presentadas por los perpetradores de manera animalizada -lo que supone la suspensión de ciertos derechos y garantías propias de lo humano-. La continuidad entre unas y otras, sin embargo, estaría dada por las figuras de los observadores: detrás de los victimarios, se muestran los testigos mudos de la escena.

La radicalidad de la muerte en estos eventos narrados conlleva no sólo un compromiso emocional sino la conflictividad propia de su puesta en discurso, de su representación.

En este sentido, en el filme, Ramsay asume la decisión de no mostrar el momento de la masacre. Los disparos de Kevin no tienen destinatarios dentro de la imagen; él está solo en el cuadro. Será mostrado de frente y de espaldas, en gestualidades teatrales -sólo su rostro dejará entrever las consecuencias de sus disparos-, pero nunca en el mismo encuadre que las víctimas. A ellas, las vemos directamente en las camillas, socorridas por médicos y bomberos, al final. Así, la masacre es construida principalmente desde los espectadores y familiares que esperan y sufren, fuera del gimnasio donde ocurre y, en menor medida, desde los gestos ficticios de Kevin. No obstante, las consecuencias de esos gestos serán contundentes a lo largo del filme.

\section{De la traducción}

En el ámbito de la Semiótica de la Cultura y, especialmente, en los trabajos de luri Lotman, la noción de semiósfera es fundamental. Si bien el espacio definido por ese concepto es variable y puede ser utilizado para dar cuenta de procesos diferentes, en diferentes niveles (algunos más abarcativos y abstractos, otros más concretos e identificables), lo que permanece inalterable en unos y otros es lo que Lotman denomina frontera. Siguiendo una definición matemática de este concepto, podemos decir que la frontera "es un conjunto de puntos que pertenecen simultáneamente al espacio interior y al espacio exterior" (Lozano, 1999, p. IV) y cuya función 
primordial es limitar la penetración de lo exterior o filtrarlo para su adaptación. Esta incorporación de lo ajeno a la semiosis es un proceso constante, que supone este trabajo de adaptación. En la frontera, precisamente, es donde tiene lugar este trabajo, que Lotman también llama de traducción.

La semiósfera supone también intercambios asimétricos entre el centro de la misma y su periferia. Normalmente, podríamos asumir que la periferia es la zona más cercana a la frontera, que presenta como riesgo último la exclusión, la expulsión y la no-existencia (el más allá de la frontera). Dentro de sus límites, encontramos la diversidad y, en muchos casos, la incorrección de ciertas prácticas que no pueden alcanzar el centro. Esta incorrección se opone a la unidad, a las normas y al lenguaje propio de quienes ocupan la posición central en los procesos de semiosis.

Más allá de esta visión espacial estratificada o asimétrica de los procesos semiósicos, la concepción de Lotman ayuda a dar entidad a esos mecanismos propios de la semiosis (aunque no excluyentes de ella) que permiten la circulación de discursos de unos espacios sociales a otros y las necesarias transformaciones/traducciones a las que deben someterse para adquirir esta movilidad. Aceptamos con él que expresar algo en otra lengua es una forma de comprenderlo y, como en la mayoría de los casos los diferentes lenguajes no son mutuamente simétricos, entonces no es posible encontrar correspondencias semánticas directas. Así, en este proceso de traducción se genera nueva información de manera constante, gracias al propio mecanismo de la semiósfera (Lotman, 2009).

Vinculado en alguna medida a los trabajos de Lotman, Umberto Eco también se ocupa de la traducción y lo hace atendiendo a diversos problemas propios de estos quehaceres.

Acude a tal fin a su propia experiencia como traductor y como autor traducido, así como a sus vivencias como lector y espectador de obras ajenas. En Decir casi lo mismo (2008), define a la traducción como el acto de entender tanto el sistema interno de una lengua como la estructura de un texto determinado en esa lengua, y construir un duplicado del sistema textual que, según una determinada descripción, pueda producir efectos análogos en el lector, ya sea en el plano semántico y sintáctico o en el estilístico, métrico, fonosimbólico, así como en lo que concierne a los efectos pasionales a los que el texto fuente tendía.

(Eco, 2008, p. 23, cursivas del autor) En esta definición, está presupuesto que la traducción se produce entre dos textos con la misma materia de la expresión. Y en tanto Eco dedica gran parte de esa obra a este tipo de trabajo de traducción, dedica también algunos capítulos a lo que él denomina traducción intersemiótica, "que ya Jakobson llamaba transmutación y otros llaman adaptación" (2008, p. 416)4. La particularidad aquí es que entre el texto fuente y el texto de llegada no sólo hay una transformación de la materia lingüística (sistema semiótico, dice Eco) sino que lo que cambia fundamentalmente es la materia de la expresión. Los ejemplos predilectos del autor hacen referencia a los pasajes de una historia en un libro a su adaptación cinematográfica, de la materia lingüística a la audiovisual.

En estos procesos de pasaje, lo que se pone en juego son conjeturas y procesos de interpretación: Para entender un texto -y con mayor razón para traducirlo- hay que formular una hipótesis sobre el mundo posible que representa. (...) una traducción debe apoyarse en conjeturas, y solo después de haber elaborado una conjetura que se le presente como plausible, el traductor puede proceder a verter el texto de una lengua a otra. O sea que, dado el espectro completo del contenido puesto a disposición por una entrada del diccionario (más 
una razonable información enciclopédica), el traductor debe elegir la acepción o el sentido más probable, razonable y relevante en ese contexto y en ese mundo posible.

(Ibíd, p. 57) Cuando lo que está en juego en el proceso de traducción son elecciones que incumben a una misma materia (lingüística) en diferentes sistemas semióticos, el trabajo del traductor es arduo. Cuando la traducción es intersemiótica, estas elecciones suponen una gama de desafíos más amplios en tanto deben reflexionar también en torno a otras materias, por ejemplo, visuales y sonoras. En los ejemplos trabajados por Eco, lo que está en juego es la necesidad de mantenerse fiel, no al autor, sino a la obra original.

Compartiremos a continuación una serie de reflexiones en torno a las decisiones que se tomaron en el proceso de traducción intersemiótica de We need to talk about Kevin. A partir de algunos ejemplos, buscaremos dar cuenta de las decisiones tomadas en la versión cinematográfica de la obra, para establecer las diferencias y las continuidades y eventualmente considerar la fidelidad de la obra de llegada en relación a la obra fuente.

\section{Desde el libro}

La primera de las cartas tiene fecha 8 de noviembre de 2000; la última, el 8 de abril de 2001, coincide con el segundo aniversario del jueves. En todas ellas el destinatario es Franklin y si bien están escritas desde el presente de Eva, posterior a la masacre, todas ellas hacen referencia fundamentalmente a su vida antes del jueves. En gran medida, a los años que van desde el 11 de abril de 1983 hasta el 8 de abril de 1999: desde el nacimiento de su hijo hasta el día de la masacre. El recorrido temporal en ellas es cronológico y los espacios mayoritariamente mencionados son las dos casas que Eva y Franklin habitan desde que se casan (un departamento en el que nace Kevin y una casa en las afueras en la que él crece y donde nace Celia). En el libro, además, tienen importancia tanto el jardín de infantes como la escuela a la que asiste Kevin.

Las cartas, según afirma Eva, son lo único que le ha permitido aliviar un poco los sufrimientos que padece desde el jueves, y en ellas dialoga extensamente con Franklin, sobre los modos en que ambos actuaron en relación a Kevin. El título del libro y del filme da cuenta de lo que Eva hace a través de estas cartas, con su marido ausente: hablar sobre Kevin y contarle todo aquello que él no pudo ver ni escuchar de su hijo mientras vivió.

En el filme, Eva no escribe. En el filme, ella no dialoga con Franklin (más que en los flashbacks).

No hay reflexiones a las que podamos acceder como espectadores en ese presente árido de la vida de Eva. El hecho de que Eva no escriba en la película, le quita a su personaje la posibilidad del desahogo que esas cartas significan para la Eva del libro. Acentúan su sufrimiento y lo hacen, si se quiere, más privado: la Eva de las imágenes es dejada aún más sola, distante y hermética.

Entre el libro y la película

En Internet es posible encontrar un guión (screenplay) de la película firmado por Lynne Ramsay y Rory Kinnear5. La fecha de este guión es 23 de noviembre del 2007. Entre esta pieza de escritura y el libro es poco lo que queda en común: la primera persona de éste es reemplazada por la exterioridad de un relato en tercera persona que, convenientemente, no incorpora ninguno de los pensamientos y reflexiones de Eva. Tan sólo sus acciones, los escenarios y algunas indicaciones de aquello que, como espectadores, debemos poder ver en su rostro. 
No obstante, lo más interesante es lo que este guión no incorpora: comienza con una parte de la escena de la masacre en la escuela y vuelve a ella al final. En el medio, sólo encontramos el recorrido cronológico de la historia de Eva y Franklin. El presente de la enunciación de las cartas, ha desaparecido.

Así, no encontramos en él ninguno de los fragmentos que, minuciosamente narrados en el libro y en la película, nos muestran a Eva con posterioridad al jueves: en su nuevo trabajo, como empleada en una agencia de viajes; comiendo sola, en su pequeña casa, omelette y vino tinto; huyendo de los familiares de las víctimas de la masacre, así como de uno de los sobrevivientes; haciendo compras en el supermercado; limpiando el frente de su casa y su auto, y asistiendo religiosamente a los horarios de visita de la cárcel en la que Kevin se encuentra detenido. También están ausentes en este guión cinematográfico los fragmentos de la representación de los espectadores de la masacre, que pueblan intermitentemente buena parte de la primera mitad de la película dirigida por Ramsay. Evidentemente, este guión disponible para su descarga es una pieza de escritura provisoria y previa, que fue re-trabajada para la versión final del filme.

En esa versión final, Ramsay decide que el pasado acomodado de Eva, próximo al american dream, debe ser contrapuesto en imágenes con su presente post-masacre, próximo a una pesadilla, así como está escrito en el libro. Por lo tanto, entre el screenplay disponible en la web y el filme hay todavía una serie de mediaciones fundamentales para la traducción intersemiótica del libro que refieren a la contraposición entre el pasado y el presente.

Del filme

La película, de este modo, cuenta dos relatos, de dos tiempos distintos, y los alterna, dándonos a ver fragmentos de un tiempo y luego del otro sucesivamente. Los primeros quince minutos, sin referencia temporal explícita alguna, muestran hasta cuatro momentos diferentes y pueden ser confusos. La caracterización de Eva es el único indicio firme de qué tiempo está siendo relatado en cada fragmento. Luego, sin embargo, el relato se divide claramente en dos tiempos, de desarrollo igualmente lineal cada uno.

Si en el libro cada carta es un viaje al pasado desde el insoportable momento presente de Eva, en el filme son dos momentos superpuestos por el montaje. El primero, comienza con la pareja de Eva y Franklin y avanza cronológicamente: la vida de Eva de soltera, cómo se conocen, la decisión de tener un hijo, sus dificultades conyugales a raíz de Kevin, la decisión de separarse, y culmina con la masacre en la escuela. La otra parte, comienza con la vida de Eva luego de la masacre y avanza también cronológicamente. Narra su nueva y penosa vida, sus visitas a Kevin en la cárcel (el abismo que los separa, que lentamente comienza a ceder), y concluye con la pregunta, que Eva nunca le había formulado antes, de por qué hizo lo que hizo.

Las palabras y las imágenes que hacen presentes a Franklin y Celia en los fragmentos del relato uno de la película son las que, por contraste, hacen tan fuerte su ausencia en los fragmentos del segundo. Por el lado del libro, conforme las cartas avanzan y el pedido del título de la historia se hace cada vez más urgente, las referencias en tiempo presente en relación a Franklin se tornan una incógnita mayor. Luego comprenderemos que ese tiempo verbal alude al modo en que Eva siente a su marido y no a su efectiva presencia como destinatario de las cartas. 
Si en la película es necesario alternar secuencias de lo que hemos llamado el relato uno y el relato dos, en el libro esto no es necesario: la escritura habilita esa presencia sucesiva de relatos correspondientes a tiempos diferentes. De hecho, en el libro, mientras Eva relata acontecimientos del pasado, va adelantando, mediante frases sueltas y pequeños párrafos a veces, cómo estos eventos se han resuelto en un momento posterior de sus vidas. Sus pequeñas victorias en relación a Kevin en momentos puntuales de la infancia, por ejemplo, se ven opacadas y anuladas automáticamente ya que este final, lo sabemos desde el comienzo en lo atinente a lo escolar, lo intuimos en lo familiar, ha sido de tragedia.

El libro comienza con la dedicatoria de Shriver "Para Terri. Un conflicto del que ambas escapamos"6 y podría ser considerado el intento por justificar la opción de no tener hijos de la autora, según sus declaraciones en una entrevista (Glaze, 2008). Entonces, si bien el libro está escrito desde la palabra de Eva y es ella quién nos entrega a los otros personajes, la centralidad que tiene en él Kevin y su vínculo con Eva, el recuento detallado de los conflictos de Kevin, la tragedia resultante de sus actos y, finalmente, los detalles que ella, como narradora, reconstruye en torno a la masacre del jueves, no permiten dudar que el centro está puesto en el hijo que Eva, en la ficción, tuvo, y que Shriver evitó.

La película, en cambio, está focalizada en Eva: es a ella a quién sigue la cámara, ella ocupa el rol protagónico. Si en el libro ella puede tomar la palabra para construirse a sí misma a la vez que se ocupa fundamentalmente de su hijo, en el filme esto no es posible: esa primera persona de la escritura (que construye muchos personajes, principalmente a Kevin) cede su lugar a una cámara que sólo observa, que no conoce las potentes reflexiones de Eva, sólo sus reacciones y, ante la cual, Kevin es visto hacer y reaccionar. En el filme no hay vecinos que denuncien a Kevin; no hay compañeros de escuela sodomizados; no hay docentes que hablen por él; no hay rondas policiales que denuncien "pequeñas travesuras"; Violetta y Alice no tienen su lugar para aportar las pistas que Eva va juntando, horrorizada y tal vez incrédula, a lo largo del libro (a pesar de que ambas sí se encuentran presentes en el screenplay provisorio del que hemos hablado antes). La película debía elegir el camino de la elipsis, es evidente. Lo que queda fuera nos habla de otros personajes en relación a Kevin (a través de Eva); lo que Ramsay nos muestra, nos hace ver a Eva en reacción frente a Kevin (casi sin terceros).

\section{De los colores}

Narrativamente, el presente de Eva en el filme es tan importante como su pasado. Además de la caracterización del personaje de Eva en uno y otro momento, los espacios por los que circula, la presencia y ausencia de personajes y fundamentalmente los comportamientos agresivos sin causa aparente de algunos de ellos (con el correr de los minutos sabremos que la causa siempre es Kevin), dan cuenta del momento presente de Eva. Pero hay toda una serie de decisiones vinculadas a los colores de los objetos y la luz que establecen una diferencia sustancial entre el pasado y el presente.

La fiesta de la Tomatina, en España, si bien es parte del relato uno, puede ser considerada como el inicio de un trabajo visual en el relato dos del filme, en el que el color rojo es predominante: lo que une esa fiesta en la que Eva participa a comienzos de los años ochenta, con su presente, está en la banda sonora. Mientras ella es levantada por la multitud, completamente manchada de rojo y filmada desde arriba, su mirada se eleva al cielo y se escuchan gritos: no se trata ya de los sonidos de la multitud que arroja tomates, sino de unos pocos jóvenes asustados por un arco que se tensa, mientras lanza flechas. Sutiles, esos segundos hacen de puente entre el tomate triturado en el cual Eva se hunde (el guión se pregunta: ¿es esto el infierno?7) y su presente, un pozo del 
cual pareciera ni siquiera intentar escapar, luego de los sucesos del jueves (si no el infierno, sin dudas su purgatorio personal).

Además de los tomates en España, la preponderancia del color rojo a lo largo del filme es evidente: la pintura que mancha su casa y su auto y que tiñe la luz que atraviesa las ventanas de uno y otro espacio; las luces fuera del colegio, cuando los bomberos desbloquean las puertas del gimnasio; las luces en la noche de Halloween y en las calles de la ciudad por las que transita con Franklin cuando jóvenes; el reloj despertador; la puerta que la profesora golpea sin poder abrir el día jueves; las latas de sopa de tomate delante de las cuales Eva se refugia de la madre de una de las víctimas en el supermercado; el vino tinto que, irremediablemente, acompaña sus omelettes de cena; la mermelada con que Kevin unta sus panes de merienda; el vagón-restaurante en que Eva come, sola; tendida en su cama, ensangrentada, después de descubrir en el patio a Franklin y Celia muertos; las luces en la calle mientras maneja y cada uno de los fragmentos del filme en los que se dedica a limpiar el frente de su casa y el parabrisas de su auto.

No obstante, el juego cromático en las imágenes del filme no se restringe sólo al rojo. En la entrada del gimnasio, mientras se van destrabando las puertas y socorriendo a los heridos, las luces de ambulancias, policía y bomberos mezclan el rojo con el azul.

El color azul está en las paredes del cuarto de Kevin en la casa-rancho y es el color que elige Eva para pintar las paredes del pequeño cuarto que ella prepara en el año 2001 para cuando Kevin recupere su libertad.

Cuando Eva regresa de la Tomatina y se reencuentra con Franklin en un cuarto de hotel, las luces que ingresan de la calle son azules. Él le pregunta si es seguro tener relaciones y ella da a entender que está dispuesta a tener un hijo8.

La continuidad y repetición de estos dos colores no es casual, ya que además fueron predominantes en algunos de los afiches promocionales del filme: Eva mirando de costado bañada en una luz roja y Kevin con el ceño fruncido, las cejas arqueadas, mirando hacia delante, en un monocromo azul (Imagen 2).

De los parecidos entre madre e hijo

Eva cierra su última carta a Franklin el 8 de abril de 2001, con una serie de confesiones sobre sus parecidos con Kevin. Desde el momento en que, de bebé, él se alejó de su seno con desagrado y ella le correspondió con un rechazo similar, pasando por la lucha con que se enfrentaron uno y otro con una ferocidad implacable a lo largo de los primeros dieciséis años de vida de él. Ese combate mudo entre Eva y Kevin habría sido el responsable, finalmente, no sólo de que Eva conociera a su hijo mejor que ningún otro a su alrededor (mejor que Franklin, por supuesto), sino finalmente también de su inevitable aproximación y cercanía, consecuencia del hecho de intentar expulsarse mutuamente lejos uno del otro (Shriver, 2007, p. 463). ¿Cómo mostrar en imágenes estos parecidos y esta lucha? ¿Cómo sugerir en el filme estas similitudes entre madre e hijo puestas en palabras en las cartas a Franklin? La primera vez que vemos a la Eva de 1999, a pocos minutos de comenzado el filme, tiene el pelo muy corto en su nuca y es mostrada de perfil: desde este ángulo, sus parecidos con el rostro de Kevin se amplifican. 
Ambos son mostrados dentro del cuadro y contrapuestos en reiteradas oportunidades a lo largo de la película. Si bien estas imágenes podrían entenderse como la evidencia de su "combate", sin duda terminan siendo también las pruebas de la cercanía entre ellos: cuando ingresan por primera vez a la casa-rancho de los suburbios, ambos están sentados en el piso de la inmensa sala de estar, con miradas perdidas; en prisión, ante la mesa durante el tiempo de visita, ambos están sentados frente a frente, en la mayor parte de las ocasiones, sin hablar; en el restaurante, en la oportunidad en que salen solos a cenar, luego de jugar en el Mini Golf; en otros planos, mientras uno de ellos está en primer lugar, frente a la cámara, el otro ocupa algún espacio en profundidad de campo; normalmente, los primeros planos y los planos detalle de los rostros, son sólo para ellos dos; Kevin saca uñas de su boca y las acomoda frente a sí en la mesa, durante la visita de su madre, y Eva saca cáscaras de huevo de su boca y las acomoda en el borde de su plato con omelette. Y, fundamentalmente, cuando la cámara toma un lavamanos lleno de agua desde abajo (desde adentro) y vemos que alternativamente Eva y luego Kevin hunden su rostro/se funden en él, vestidos con ropa de igual color.

Lo que en el libro está construido como una suposición por parte de Eva, en el filme está mostrado como una posibilidad: estas semejanzas entre madre e hijo contribuyen a explicar la decisión de él de dejar con vida a su madre9.

Todas estas transformaciones no son parte, necesariamente, de las cartas que Eva escribe, sino que pertenecen a esa gama de decisiones que deben ser tomadas en el trabajo de traducción intersemiótica. En este sentido, un último elemento que deseamos resaltar es el trabajo con la música dentro del filme.

De la música y la banda sonora

Antes analizábamos el uso de la banda sonora durante la fiesta de la Tomatina, especialmente en el momento en que Eva parece reflexiva, mientras se hunde en ese líquido rojo.

De igual modo, la banda sonora funciona a lo largo de la película presentando o resolviendo conflictos que no aparecen mayormente desarrollados en imágenes.

Un episodio de gran tensión para Eva está apenas sugerido a partir de una frase en la banda sonora, sin la correspondiente imagen. Mientras Eva espera a Kevin en la sala del hospital, luego de que se quiebra el brazo, vemos su estado de nerviosismo ante el temor de ser expuesta ante la médica como la responsable de esa fractura. Segundos antes, hemos escuchado la voz en off de Kevin que afirma, casi como una amenaza: "Puedo ver a la doctora yo solo" (“I can see the doctor by myself”, 43'10") y así entendemos el temor a que Kevin pueda contarle las circunstancias de su caída.

De igual modo, podemos mencionar, al menos, tres elementos que tienen importancia en la película, que no aparecen explícitamente en el libro y que, sin embargo, podrían ser consideradas decisiones correctas tomadas por parte de la directora en su trabajo de traducción.

La primera, es el instrumento con el que es asociada Eva en algunos pasajes del filme. Se trata probablemente de una cítara. En cualquier caso, es un instrumento de cuerda, no convencional (no se trata de una guitarra) que aparece en momentos de gran exposición y tensión para Eva: saliendo del Tribunal, durante los juicios o al encontrarse en la calle con los familiares de las víctimas. 
En segundo lugar, el ruido del regador del parque de la casa-rancho. Es el primer ruido que escuchamos al comenzar el filme (00'34"). Lo escuchamos en diferentes momentos de las escenas en esa casa, si bien está asociado al momento en que Eva descubre a Franklin y a Celia en el parque. Pero también es superpuesto a ciertas imágenes de Kevin en otros espacios.

Por ejemplo, cuando se para en el escenario del gimnasio, de espaldas a la cámara, y saluda a una supuesta platea, vacía, arco en mano, luego de que se escucharan los disparos y los gritos, luego de que Eva reingresa en la casa, desde el patio en el que el sistema de riego sigue funcionando.

En tercer y último lugar, podríamos recorrer las canciones que forman parte de la banda sonora del filme. No estamos en condiciones de realizar aquí ese trabajo de forma extensa, aunque sí deseamos retomar algunos fragmentos de la canción con la que directora decide concluir el filme: Mother's last words to her son, de Washington Phillips.

El tema, en su versión original, corresponde a 1927, y esta es la versión que Ramsay decide incluir en el filme. Junto a la materialidad sonora propia de los discos antiguos, es evidente la ajenidad temporal de la canción en relación al presente del relato. No obstante, esta extrañeza que genera en el espectador contribuye a tomar conciencia de ella y a acompañar ese momento de la confesión de Kevin, que pareciera marcar justamente el fin del combate con su madre: por primera vez el reconocimiento de la atrocidad de lo hecho, el surgimiento de la duda y el silencio en el lugar de las ciegas certezas anteriores.

No puedo olvidar ese día, cuando mi querida madre me dijo dulcemente: “Te estás yendo, hijo querido.

Siempre has sido la alegría de tu madre"10.

La canción comienza a escucharse, desde el inicio instrumental, cuando Eva abraza fuertemente a Kevin para despedirse. Lo único que podemos oír, sin embargo, son sus versos finales: Ahora cuando pienso en mi madre querida, cuán seguido intentó y consiguió, alegrar mi mente inquieta, perdida en sendas erradas, mientras me decía "Aceptá tu camino".

Eva finalmente puede tomar su lugar de madre: acompañar a su hijo en el camino que le espera, haciéndole saber también las responsabilidades que le caben por las decisiones tomadas. Y Kevin, finalmente, pareciera agradecer la compañía de su madre y comenzar a comprender más cabalmente los alcances de la masacre.

\section{Masacres en escuelas}

Dentro de las escuelas, la muerte habilita reflexiones específicas y también procesos específicos de duelo, más allá de los familiares extra-escolares11. Ahora, cuando los responsables de esas muertes son compañeros, son los propios estudiantes, entonces el evento se torna realmente intolerable.

La radicalidad de estas muertes, además, cuestiona a la institución escolar como espacio de circulación de la palabra y encuentro con otros diferentes; como el lugar de la transmisión del conocimiento y de la construcción de un futuro posible; como espacio de subjetivación de los sujetos e incluso como un lugar al que la violencia a priori le resulta ajena (baste mencionar la cantidad de textos dedicados a indagar y conjurar las diferentes violencias en las escuelas y la etiqueta de "violencia escolar" con la que los medios muchas veces justifican la 
inclusión allí de "lo noticiable" que estos hechos suponen); todos estos elementos son los que se conmueven con las masacres en escuelas. Incluso la muerte de compañeros y docentes por mano de otros estudiantes pareciera convocar la figura de la traición12.

Todas las justificaciones que Kevin argumentaba, fundamentalmente a través de los medios de comunicación (pocas de ellas presentes en la película), desaparecen al final del libro y del filme: dos años después del jueves, él está a punto de ser trasladado a una cárcel de adultos (cumple dieciocho años) y Eva, por primera vez, le formula esa pregunta: ¿por qué?13 Y por primera vez, Kevin, abatido, golpeado y agradecido por la presencia de su madre de visita en la cárcel, responde que ya no lo sabe. Antes, creía saberlo. Ahora ya no.

La incertidumbre de Kevin probablemente sea la más intranquilizadora de las respuestas para el lector/espectador.

Coincidimos con Burucúa y Kwiatkowski (2009) en que las masacres nos ponen frente al cuestionamiento por lo que nos hace humanos y su representación en We need to talk about Kevin, en sus indefiniciones, nos permite, de alguna manera, ese distanciamiento necesario ante la masacre a partir de su representación: la falta de respuesta del libro y de la película no son más que la invitación para el lector/espectador a iniciar estas búsquedas.

Ahora, ¿qué sucede con la escuela representada? ¿Cuál es su margen de acción en We need to talk about Kevin? ¿Nos permite reflexionar sobre el lugar de nuestras escuelas en relación a las situaciones de violencia?

\section{Antagonismo invisible}

La escuela es una institución en la que nos encontramos con la diferencia. De acuerdo al tipo de espacio familiar del que cada uno provenga, el aprendizaje de lidiar con la diferencia y con los diferentes, tiene lugar mayormente en la escuela. Y por lo tanto, es el espacio posible para el conflicto.

Chantal Mouffe (en Triquell y Ruiz, 2014) afirma que el conflicto es inherente a los vínculos en sociedad: en las sociedades humanas una de sus dimensiones fundamentales es la del conflicto, la de los antagonismos. Estos antagonismos permiten construir un posicionamiento propio, en el marco de la dinámica "nosotros-ellos": en tanto se puede reconocer el conflicto, es posible la toma de posición y con ella, surge la posibilidad de tomar decisiones que comienzan a delimitar un nosotros y un ellos.

Triquell y Ruiz afirman que "para Mouffe, el desafío de la democracia pluralista no es eliminar el antagonismo sino 'domesticarlo', en la forma que ella denomina 'agonismo'” (2014, p. 130). La relación de agonismo reconoce la legitimidad de los oponentes en conflicto.

Es decir, busca transformar una relación de antagonismo en la que las partes no reconocen ninguna base común, en una relación nosotros/ellos en la que se reconoce la legitimidad de sus oponentes (lbíd., p. 131).

Ahora bien, para lograr la construcción de relaciones agónicas, es necesario que el conflicto tenga lugar, que pueda visibilizarse. En We need Kevin se encarga de que esa expresión no se produzca nunca. La escuela, para él, no es el escenario posible de estas disputas, ya que se encarga de borrarlas una a una, de invisibilizarlas. La 
única persona que logra reconstruirlas, aparentemente sólo a posteriori (y en gran medida, sólo en el libro) es Eva.

Hasta el momento de la masacre, Kevin logra evadir todo lo que es del orden de la expresión del conflicto con otros que no sean su madre y en espacios vinculados a lo público (diferentes a su hogar). Y Eva queda sola en este reconocimiento: no logra compartirlo con Franklin, menos aún hacerlo público, hasta que es demasiado tarde.

Es más: el antagonismo radical que expresan las acciones de Kevin no tienen como fin la eliminación de esas personas a las que asesina, no son ellos sus oponentes (aunque sí sus víctimas). De hecho, podríamos intuir que no los reconoce siquiera como oponentes, sino más bien como las piezas clave de un mensaje dirigido a la sociedad en su conjunto. De hecho, el cuidadoso proceso de selección de cada una de las víctimas, atiende a características en tanto representantes de "tipos ideales" (cf. nota 13), antes que de individuos concretos.

La búsqueda de un agonismo que aborte la masacre sería, por lo tanto, imposible.

Parece pertinente aquí recuperar algunas reflexiones elaboradas por Elvira Martorell (2006) en relación a la violencia en las escuelas: (...) que el instinto de destrucción es algo basal en el ser humano, que la violencia está en nosotros mismos y que justamente el pacto fraterno se constituye para preservar la vida de los hermanos del clan (...) la sociedad está permanentemente en peligro de volver, diría Hobbes, "al estado de naturaleza", diría Freud "al estado de la horda". No hay nada asegurado en esto, en este pasaje de naturaleza a cultura, es necesario constantemente renovar el pacto. (Martorell, 2006, p. 22).

Martorell afirma que la violencia es parte inherente a los seres humanos: desde otros marcos de referencia, la tesis de Mouffe citada antes. En esta argumentación, la violencia es algo con lo que las instituciones educativas deben lidiar, algo que deben reconocer que está allí para poder trabajarlo. En We need to talk about Kevin lo que se aborta justamente es la posibilidad de este trabajo con la violencia, porque Kevin la esconde, la disfraza, la evita.

Todo aquello que en el libro aparece tematizado como indicios, como pistas, identificado en las acciones de Kevin en el ámbito de lo público (en la calle, en la escuela, en el jardín, en un baile), son sin embargo elementos que solo Eva puede considerar. Y, sobre todo, elementos que la película no recupera. Por lo tanto, en ella los indicios y sobre todo, la responsabilidad, quedan restringidos al ámbito de lo doméstico-privado. Todo pareciera indicar que, por ejemplo, la escuela no es la causa del accionar de Kevin pero que tampoco tiene nada que hacer para evitarlo.

Eva pareciera luchar contra la idea de que la responsabilidad en relación a Kevin es toda de ella y sólo de ella, por no haberlo deseado lo suficiente, por no haber logrado hacer lo que otras madres hacen con sus hijos, desde el mismo comienzo. Franklin no logra ver a Kevin y, por lo tanto, no alcanza a anticipar sus movimientos. El "necesitamos hablar de Kevin" del título está dirigido a él, bajo el género epistolar póstumo que Eva le dedica. Pero bien podría tratarse de una exhortación dirigida también a los lectores y a los espectadores.

We need to talk about Kevin se aleja de las prescripciones y de los componentes didácticos en relación a sus espectadores. En buena medida, solo instala interrogantes-límite. Por lo tanto, no haremos aquí lo que la historia 
evita tan exitosamente. Sólo nos interesa dejar claro, hacia el final, que en el proceso de traducción intersemiótica hay diferencias entre el libro y la película, también en relación al lugar que le cabe a la escuela, en tanto ese "adentro" del "afuera de la casa" (Martorell, 2006, p. 23).

Tanto la película como el libro nos "hablan de Kevin": en uno, hay una diversidad de actores que intervienen y que podrían, eventualmente, devenir auxiliares (aunque esto no ocurra); en la otra, el número de estos actores se reduce y la escuela pasa a ser simplemente el escenario de una acción que pareciera inevitable. Kevin saluda a la platea, vacía, arco en mano, una vez que su performance terminó.

Notas

1. La propia Eva nombra el día de la masacre como el jueves que le quitó su vida. Kevin encierra el día jueves 8 de abril de 1999, a tres días de cumplir dieciséis años, a once personas cuidadosamente elegidas en el gimnasio de la escuela secundaria a la que asiste. Allí, desde la altura, dispara sobre ellos flechas hasta producir la muerte de nueve de ellos. Son siete compañeros y compañeras, un trabajador de la cantina del colegio y una docente. Hacia el final del libro y de la película nos enteraremos que, previamente y antes de salir de su casa, Kevin ha asesinado también a su padre y a su pequeña hermana en el jardín. De esta forma, la tragedia del jueves para Eva es doble: pública e íntima.

2. Como ejemplos, podemos mencionar Elephant (2003), de Gus van Sant y Klass (2007), de Ilmar Raag.

3. El trabajo que desarrollamos en este escrito es fruto de nuestra inserción en un proyecto colectivo de investigación que indaga en representaciones audiovisuales de conflictos contemporáneos. En ese colectivo, mi trabajo está centrado en representaciones de conflictos en escenarios educativos. El título del Proyecto es "Imágenes en conflicto: Construcciones audiovisuales de la conflictividad social en la Argentina contemporánea. Segunda etapa." Está dirigido por la Dra. Ximena Triquell y codirigido por el Mgter. Santiago Ruiz y ha sido aprobado y subsidiado por la Secretaría de Ciencia y Técnica de la Universidad Nacional de Córdoba, para el período 2014-2015.

4. Este uso del término adaptación se distingue de la forma en que se lo comprende en la obra de Lotman, para devenir el uso habitual, cotidiano, propio del sentido común, que supone el pasaje de una obra desde la materia lingüística a la audiovisual/fílmica.

5. El mencionado screenplay puede encontrarse en: http://www.pages.drexel.edu/ ina22/splaylib/ScreenplayWe_Need_to_Talk_About_Kevin.pdf (última visita: octubre de 2014).

6. La versión original en inglés dice: "For Terri. One worst-case scenario we've both escaped”. Edición de 2003, publicada por Counterpoint, miembro del Grupo Editorial Perseus, en Nueva York, Estados Unidos.

7: "A mass of half-naked teenage bodies writhe together, piled on top of one another, screaming and yelling, covered in a viscous, blood-red liquid. Is this hell?" (Ramsay y Kinnear, 2007, p. 10).

8: Inmediatamente después de esta escena, vemos unas imágenes de células dividiéndose: se da a entender que corresponden al embarazo en curso. En los créditos, sin embargo, se menciona que son células de cáncer de mama en proceso de división. 
9: La escena de la fotografía dada por desaparecida por Eva, que Kevin tiene con él en prisión, de una joven Eva en Amsterdam, por ejemplo, contribuye a consolidar esta hipótesis.

10: La letra completa de la canción dice: "I never can forget the day / When my dear Mother did sweetly say / You are leavin', my darling boy / You always have been your mother's joy. Now as you leave in this world to roam / You may not be able to get back home / But remember Jesus, who lives on high / And is watchin' over you with a mighty eye. The world is so full of old sin and woe / And many sorrows everywhere you go / But remember Jesus, who's everywhere / You get in trouble now, he'll meet you there. If you'll bow down before his face / And trust in him for his saving grace, now / And you have a burden, he'll make them light / And he sure will guide you all in the right. Now when I think of my Mother dear / How often she did, and try to cheer / My wandering mind, whilst going astray, / By saying, "Son, accept the way." Todos los fragmentos en cursiva han sido traducidos en el cuerpo del texto.

11. Un intento específico en este sentido fue llevado adelante por el equipo responsable de la Revista del Ministerio de Educación de la Nación, El monitor de la educación -Nueva época. En el número 12 de la revista, el dossier temático fue dedicado a "El lugar de la escuela ante el dolor". Puede consultarse en: http://www.me.gov.ar/monitor/nro12/index.htm (última visita: agosto de 2014).

12. Un buen ejemplo de investigaciones desde un abordaje sociológico de las violencias en las escuelas es el libro dirigido por Carina Kaplan (2006). Desde una perspectiva de intervención, enfocado desde los docentes en escuelas, puede consultarse el material por el Instituto de Capacitación e Investigación de los Educadores de Córdoba (2014).

13. No podemos profundizar en esto aquí, pero, a grandes rasgos, Kevin asume completa responsabilidad por lo hecho, justamente porque le permite confrontar a la audiencia de la televisión que lo observa con una imagen de sociedad enferma de consumo, y de consumo de imágenes violentas y biografías de asesinos. En esa serie, él es capaz de distinguir entre asesinos inteligentes y memorables capaces de elaborar un metódico plan de acción y con objetivos claros para transmitir al resto de la sociedad-dignos por lo tanto de su fama y de su lugar en la historia de la comunidad-, de aquellos meros amateurs, solo responsables de un golpe de suerte o de algún trastorno menor. Él, por cierto, se ubica a sí mismo entre los primeros. A esta autovaloración contribuye el hecho de que sus víctimas han sido cuidadosamente elegidas entre los más populares de la escuela, representando un abanico de diversidad en sentido amplio: hay latinos, negros y blancos; hay gays y heterosexuales; deportistas, nerds y artistas; adolescentes comprometidos con su belleza o con causas políticas partidarias.

\section{Bibliografía}

Albert, L., Wolf, D. y otros (productores) y Van Sant, G. (director/ guionista). (2003) Elephant [película]. Estados Unidos: HBO, Fine Line Features y Meno Films.

Burucúa, J. E. y Kwiatkowski, N. (2009). "Masacres antiguas y masacres modernas. Discursos, imágenes, representaciones". En Mudrovcic, M. I. Pasados en conflicto. Representación, mito y memoria (pp. 61- 85). Buenos Aires: Prometeo. 
Eco, U. (2008[2003]). Decir casi lo mismo. Experiencias de traducción. Barcelona: Lumen. Fox, J., Roeg, L. y Salerno, R. (productores) y Ramsay, L. (director). (2011). We need to talk about Kevin [película]. Reino Unido/ Estados Unidos: BBC Films, UK Films Council y Rockinghorse Films.

Glaze, A. (28 de agosto de 2008) "School Killers”, Disponible en: www.pagina12.com.ar/diario/psicologia/9110487. Recuperado octubre de 2014.

Gramakovski, E. (productor) y Raag, I. (director/ guionista). (2007) Klass [película]. Estonia: Amrion y Eesti Televisioon.

Instituto de Capacitación e Investigación de los Educadores de Córdoba (2014). Los conflictos en la escuela. Una perspectiva para su comprensión y abordaje. Córdoba: Unión de Educadores de la Provincia de Córdoba.

Kaplan, C. (dir.) (2006). Violencias en plural. Sociología de las violencias en la escuela. Buenos Aires: Miño y Dávila.

Lotman, I. (2009). Culture and explosion. Berlin: De Grouter Mouton.

Lozano, Jorge (1999). "Prólogo a la versión española", en Lotman, I. Cultura y explosión. Lo previsible y lo imprevisible en los procesos de cambio social. Barcelona: Gedisa. Disponible en: https://pendientedemigracion.ucm.es/info/especulo/numero11/lotman2.html. Recuperado octubre 2014.

Martorell, E. (2006). "De la violencia a la subjetividad. Una interrogación en torno a la posibilidad de refundar el territorio escolar". En AAVV. Miradas Interdisciplinarias sobre la Violencia en las Escuelas. Buenos Aires: Ministerio de Educación, Ciencia y Tecnología de la Nación.

Otero, D. (2013). "Tenemos que hablar de Kevin: una madre, un hijo y un acto”, en Ética y Cine Journal. UBA/UNC/UIO. Buenos Aires. Disponible en: http://journal.eticaycine.org/Tenemos-que-hablar-de-Kevin-Una. Recuperado agosto de 2013.

Ramsay, L. y Kinnear, R. (2007). We need to talk about Kevin. Screenplay. [en línea]. Disponible en: http://www.pages.drexel.edu/ ina22/splaylib/Screenplay-We_Need_to_Talk_About_Kevin.pdf. Recuperado octubre de 2014.

Schriver, L. (2007). Precisamos falar sobre o Kevin. Río de Janeiro: Editorial Intrínseca.

Triquell, X. y Ruiz, S. (2014). "La dimensión política de los discursos sociales". En Revista De Signos y Sentidos, $15,125-138$.

Abstract:

This article analyzes the processes of literary linguistic matter transformation in cinematographic discourse, focusing in one particular case: the book by Lionel Shriver, We need to talk about Kevin,and Lynne Ramsay's film version. In the first place, I am interested in the transformations of linguistic matter that take place throughout the 
intersemiotic translation process. In the second place, I share some reflections about the disputes on conceptions about schools both in the book and in the film, considered in terms of the political.

Key words:

intersemiotic translation - discourse - massacres in schools - the political - conflicts in schools.

\section{Resumo:}

Este trabalho aborda os processos de transformação da matéria linguística em discurso cinematográfico a partir de um caso específico: We need to talk about Kevin, livro de Lionel Shriver (2007), adaptado ao cinema por Lynne Ramsay (2011). Em primeiro lugar, nos interessa centralizar o foco nas transformações que sofre a matéria linguística em sua tradução intersemiótica à outra materialidade significante. Em segundo lugar, é pertinente compartilhar algumas reflexões acerca das disputas -consideradas, no que se refere ao político-que ocorrem dentro da instituição escolar e são trazidas à tona tanto no livro quanto no filme.

Palavras chave:

tradução intersemiótica; discurso; massacres em escolas; o político; conflitos em escolas.

Dimensiones de una masacre en la escuela: traducción intersemiótica en We need to talk about Kevin fue publicado de la página 59 a página75 en Cuadernos del Centro de Estudios de Diseño y Comunicación № 61 